\title{
Draft genome sequences of two Streptomyces albidoflavus strains DEF1AK and DEF147AK with plant growth- promoting and biocontrol potential
}

\author{
Andrea Kunova ${ }^{1 *}$ (D, Paolo Cortesi ${ }^{1}$, Marco Saracchi ${ }^{1}$, Guy Migdal $^{2}$ and Matias Pasquali ${ }^{1}$
}

\begin{abstract}
Purpose: Bacteria belonging to the Streptomyces genus can be exploited in environmentally friendly approaches to food safety. Genome information can help to characterize bioactive strains opening the possibility to decipher their mechanisms of action.

Methods: The biocontrol and plant growth-promoting activity of two Streptomyces spp. strains, DEF1AK and DEF147AK, were assessed in vitro and in planta. The genome sequences were determined using the lllumina NextSeq sequencing system and were assembled using EvoCAT (Evogene Clustering and Assembly Toolbox).

Result: Streptomyces spp. DEF1AK and DEF147AK were able to improve seed germination and early plant development of maize, wheat, and tomato and inhibited the mycelium growth of diverse fungal plant pathogens in vitro. The genome sequence analysis identified both strains as S. albidoflavus ( $99 \%$ sequence identity). Both genomes were of 7.1-Mb length with an average GC content of 73.45\%. AntiSMASH and MIBiG analyses revealed strain-specific sets of secondary metabolite gene clusters in the two strains as well as differences in the number and type of duplicated genes.

Conclusion: The combination of the biological activity and genomic data is the basis for in-depth studies aimed at the identification of secondary metabolites involved in plant growth-promoting and biocontrol activity of Streptomyces spp. The comparison of unique genomic features of the two strains will help to explain their diverse biocontrol and plant growth-promoting activities and warrant targeted functional genomics approaches to verify their mechanisms of action.
\end{abstract}

Keywords: Antagonism, Biological control, Genome mining, Secondary metabolites

\section{Background}

Streptomyces spp. are Gram-positive filamentous bacteria ubiquitous in the soil as free-living organisms and symbionts of plants and animals (Seipke et al. 2012). They are renowned for producing a wide variety of biologically active secondary metabolites, and therefore, there are increasing attempts to apply them in agriculture as plant

\footnotetext{
*Correspondence: andrea.kunova@unimi.it

'Department of Food, Environmental and Nutritional Sciences (DeFENS),

University of Milan, Via Celoria 2, Milan, Italy

Full list of author information is available at the end of the article
}

growth promoters or biological control agents (BCA) (Xiao et al. 2002; Bonaldi et al. 2014; Colombo et al. 2019b, a; Liu et al. 2019). While until 2010, less than 10 reports were published yearly with the keywords 'Streptomyces' and 'biocontrol', in the last 10 years, 50-80 scientific papers have been published each year (www. scopus.com). This indicates increasing interest in the research for alternative methods to manage plant diseases.

Despite a large number of potentially active strains with good antagonistic activity against a variety of plant pathogens, only two Streptomyces-based products have

(c) The Author(s). 2021 Open Access This article is licensed under a Creative Commons Attribution 4.0 International License, which permits use, sharing, adaptation, distribution and reproduction in any medium or format, as long as you give appropriate credit to the original author(s) and the source, provide a link to the Creative Commons licence, and indicate if changes were made. The images or other third party material in this article are included in the article's Creative Commons licence, unless indicated otherwise in a credit line to the material. If material is not included in the article's Creative Commons licence and your intended use is not permitted by statutory regulation or exceeds the permitted use, you will need to obtain permission directly from the copyright holder. To view a copy of this licence, visit http://creativecommons.org/licenses/by/4.0/ 
been registered so far for use in agriculture, based on $S$. lydicus WYEC 108 (Actinovate ${ }^{\circ}$ ) and S. griseoviridis K61 (Mycostop ${ }^{\circ}$ ). Among the main problems hindering the successful use of new BCAs is their variable performance in field conditions (Velivelli et al. 2014; Chen et al. 2016), possibly also due to the variable expression and production of bioactive molecules.

The expression of many bioactive molecules might be silenced in sub-optimal growth conditions, or on the other site, specifically activated by the presence of a specific elicitor (Wang et al. 2013). In Streptomyces, genes for the biosynthesis of secondary metabolites are mostly clustered and their expression is tightly regulated (Čihák et al. 2017). The genome analysis of bioactive strains can provide information about the secondary metabolite composition and can help understanding how the expression of these bioactive molecules is regulated (Lee et al. 2020).

In order to get a holistic view on the bioactive potential of two Streptomyces spp., DEF1AK and DEF147AK, their biocontrol and plant growth promotion activity were assessed and the draft genome sequences were obtained to identify secondary metabolite clusters possibly responsible for the biocontrol activity.

\section{Results}

Biocontrol potential of Streptomyces spp. in vitro and in planta

Both Streptomyces spp. DEF1AK and DEF147AK showed a significant ability to limit fungal growth of different fungal genera in dual culture assay (Fig. 1); however, DEF147AK showed consistently higher biocontrol activity in vitro.
The two strains were effective also when associated with the plant (Table 1, Fig. 2). Surprisingly, in association with wheat seedlings, DEF1AK was able to reduce the symptoms of both Fusarium root rot and Fusarium foot rot to a higher extent than DEF147, even though it showed lower in vitro inhibition of Fusarium pathogens. In particular, $45 \%$ of DEF1AK-treated plants were symptomless at the crown level, while only $5 \%$ of control plants did not show any symptoms.

\section{Effect of Streptomyces spp. on seed germination and biomass dry weight in vivo}

The plant growth-promoting potential of Streptomyces spp. DEF1AK and DEF147AK was tested by evaluating their effect on seed germination of various mono- and dicotyledonous plants (Fig. 3) and on the biomass accumulation after 1 month of cultivation (Table 2). DEF1AK in general did not influence the seed germination of tested species, only in the case of savoy cabbage it increased the seed germination by almost $10 \%$, while it had a negative impact on lamb lettuce germination $(25 \%$ decrease in germination). On the other hand, DEF147AK improved the germination of monocotyledonous plants (10\% increase in maize and wheat), while it generally had a negative impact on the dicotyledonous plant germination, except tomato (no change) and rocket (8\% increase).

After 1 month of growth, DEF1AK only slightly improved the biomass dry weight of maize and tomato (not statistically significant). DEF147AK instead significantly improved the biomass dry weight of maize, tomato, rocket, and lettuce (Table 2).

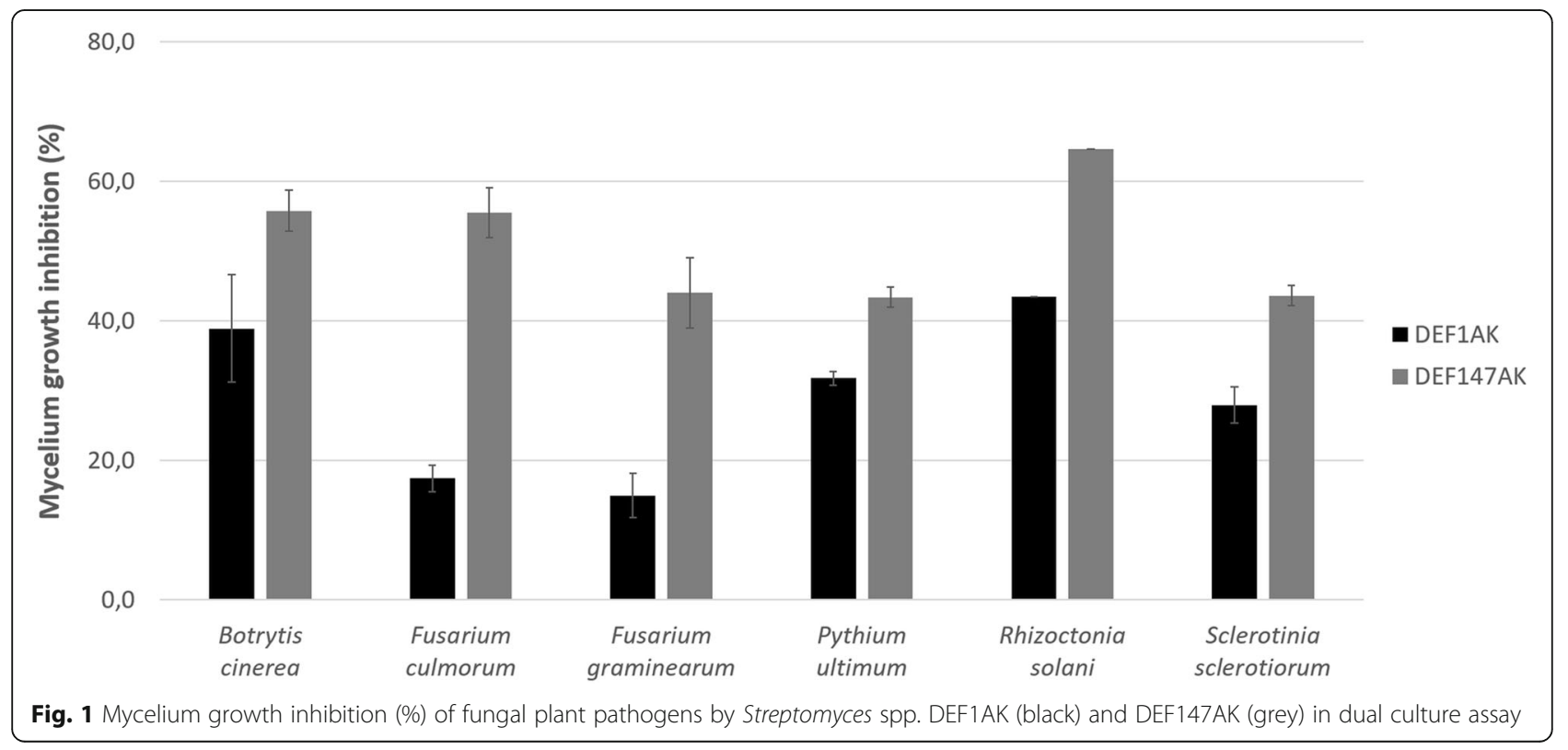


Table 1 Protection indices (\%) of Streptomyces spp. DEF1AK and DEF147AK against Fusarium root rot (browning extension and browning index) and Fusarium foot rot (crown necrosis) symptoms caused by Fusarium graminearum Fg 8/1, on wheat seedlings (Triticum aestivum 'Bandera')

\begin{tabular}{lll}
\hline & DEF1AK & DEF147AK \\
\hline Reduction of browning extension (4dai) & $17.60 \%$ & $0.00 \%$ \\
Reduction in browning index (6dai) & $49.56 \%$ & $18.39 \%$ \\
Reduction of crown necrosis (6dai) & $57.02 \%$ & $31.74 \%$ \\
\hline
\end{tabular}

dai $=$ days after pathogen inoculation

\section{Draft genome analysis of Streptomyces spp. DEF1AK and DEF147AK}

The sequencing and assembly statistics for the two strains are listed in Table 3.

Phylogenetic strain attribution was carried out using a Streptomyces multilocus sequence type (MLST) analysis (Jolley and Maiden 2010), and the closest related type strain to both DEF1AK and DEF147AK was Streptomyces albidoflavus DSM $40455 \mathrm{~T}$. Indeed, MLST analysis is the most appropriate method for correct identification of closely related Streptomyces species belonging to the S. albidoflavus clade, which share the same 16S rDNA sequence (Hain et al. 1997; Guo et al. 2008). The average nucleotide identity (ANI) implemented in EZBioCloud (Yoon et al. 2017) determined ANI equal to $99.04 \%$ and 99.06\% by comparing S. albidoflavus DSM $40455 \mathrm{~T}$ to DEF1AK and DEF147AK, respectively. By comparing DEF1AK and DEF147AK genomes, ANI = 99.91\% was obtained, suggesting that the two strains belong to the same species.

Both genomes contained more than 6000 CDS, and among these, $83 \%$ were classified into 23 clusters of orthologous proteins, such as transcription, amino acid transport and metabolism, carbohydrate transport and metabolism, and signal transduction (Huerta-Cepas et al. 2016, 2017). Almost 30\% of genes were poorly characterized with unknown function (Supplementary file 1). The similarity comparison with the PkGDB Synteny statistics (Vallenet et al. 2019) revealed that 6534 (98.21\%) CDS are organized in a single conserved block (synton) between DEF1AK and DEF147AK.

AntiSMASH (v5.0.0) and MIBiG (v4.1) analysis predicted a total of 29 and 33 secondary metabolite biosynthetic clusters in DEF1AK and DEF147AK, respectively (Blin et al. 2019). To get a better insight into the prevalence of different secondary metabolite clusters within the $S$. albidoflavus clades, the AntiSMASH analysis was performed also for the type strain S. albidoflavus DSM 40455 T, a recently sequenced S. albidoflavus ACT 77 (Pylro et al. 2019), and S. albidoflavus SM 254, whose complete genome sequence is available (Badalamenti et al. 2016). Both DEF1AK and DEF147AK strains encoded complete gene clusters for the synthesis of well-known terpene geosmin responsible for the typical earth-like smell common for streptomycetes, a siderophore desferrioxamine $B$, or stress-protectant osmolyte ectoine. There were multiple gene clusters encoding type-a polyketide synthases (t1pks) and non-ribosomal peptides (NRP) - the most common enzymes responsible for the biosynthesis of a variety of secondary metabolites. They showed a different level of homology to clusters coding for known antifungal and antibacterial molecules (Supplementary file 2) suggesting their putative role as biocontrol and plant interaction molecules (Vesselinova et al. 1991; Li et al. 2015; Chevrette et al.

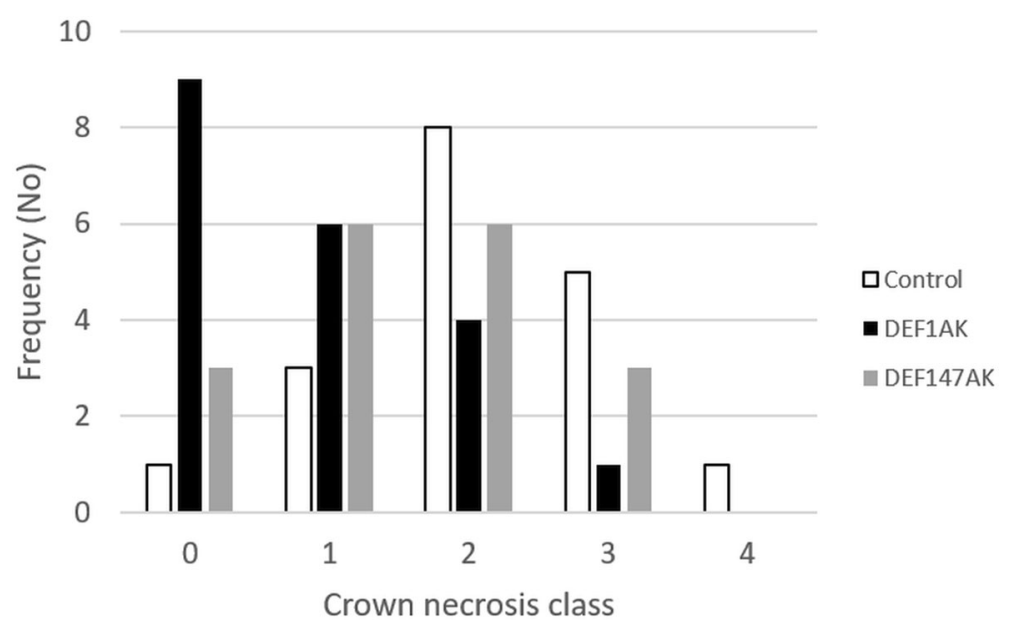

Fig. 2 Effect of Streptomyces spp. DEF1AK (black) and DEF147AK (grey) treatment on Fusarium foot rot (FFR) symptoms severity caused by Fusarium graminearum Fg 8/1, on wheat seedlings (Triticum aestivum 'Bandera') 6 days after fungus inoculation. Scale used in FFR severity evaluation at the crown level: $0=$ symptomless; 1 = slightly necrotic; 2 = moderately necrotic; $3=$ severely necrotic; $4=$ completely necrotic (Colombo et al. 2019b) 


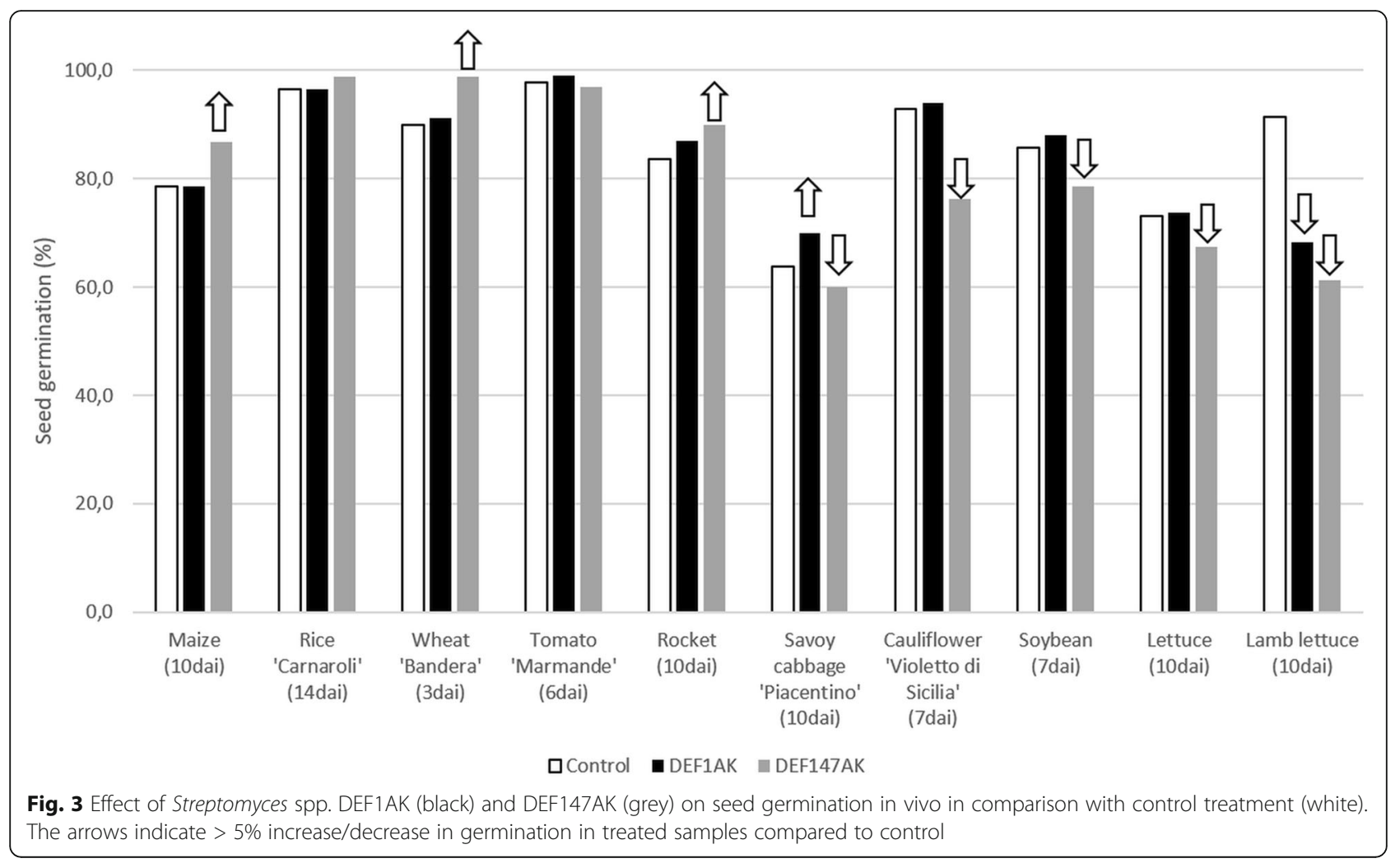

2019). Although all analysed strains encode biosynthetic pathways for the production of cyclic depsipeptides or lanthipeptides, there seem to be differences in the final secondary metabolite produced (antimycin or candicidin, AmfS or SapB). We hypothesize that the combination of particular secondary metabolites produced by a specific strain can, in the end, result in different plant growthpromoting or biocontrol activity. Given the influence of the genome completeness on the output of AntiSMASH analysis, the actual production of these secondary metabolites will be investigated in the future.

\section{Conclusions}

The Streptomyces genus is an enormous reservoir of bioactive molecules exploited mainly in medicine and, until now, only to a minimal extent in agriculture. However, their ubiquitous presence in soils and their association with plants as epi- or endophytes makes them an ideal resource for improving plant productivity and health (Seipke et al. 2012; Jauri et al. 2016).

In this paper, we analysed two Streptomyces spp. strains identified as S. albidoflavus based on genomic data, with $99.91 \%$ average nucleotide identity between

Table 2 Effect of Streptomyces spp. DEF1AK and DEF147AK on plant dry weight ( $\mathrm{g}$ ) after 1 month of growth in vivo

\begin{tabular}{|c|c|c|c|c|c|c|}
\hline & & Control & DEF1AK & DEF147AK & No. plants & $P$ value ${ }^{c}$ \\
\hline \multirow[t]{9}{*}{ Dry weight (g) } & Maize & $0.63 \pm 0.06^{a} b^{b}$ & $0.69 \pm 0.06 \mathrm{ab}$ & $0.83 \pm 0.04 a$ & 20 & 0.0263 \\
\hline & Wheat & $0.14 \pm 0.05 \mathrm{~ns}$ & $0.14 \pm 0.04 \mathrm{~ns}$ & $0.15 \pm 0.04 \mathrm{~ns}$ & 20 & 0.553 \\
\hline & Tomato & $0.25 \pm 0.03 b$ & $0.28 \pm 0.04 a b$ & $0.30 \pm 0.07 a$ & 20 & 0.0124 \\
\hline & Rocket & $0.12 \pm 0.02 b$ & $0.12 \pm 0.02 b$ & $0.18 \pm 0.03 a$ & 20 & $1.11 \times 10^{-11}$ \\
\hline & Savoy cabbage & $0.12 \pm 0.04 \mathrm{~ns}$ & $0.09 \pm 0.03 \mathrm{~ns}$ & $0.08 \pm 0.05 \mathrm{~ns}$ & $10^{*}$ & 0.0977 \\
\hline & Cauliflower & $0.16 \pm 0.04 \mathrm{~ns}$ & $0.17 \pm 0.04 \mathrm{~ns}$ & $0.14 \pm 0.05 \mathrm{~ns}$ & 20 & 0.0971 \\
\hline & Soybean & $0.35 \pm 0.08 \mathrm{~ns}$ & $0.34 \pm 0.06 \mathrm{~ns}$ & $0.30 \pm 0.06 \mathrm{~ns}$ & 20 & 0.0655 \\
\hline & Lettuce & $0.16 \pm 0.04 b$ & $0.13 \pm 0.03 b$ & $0.21 \pm 0.04 \mathrm{a}$ & 20 & $9.21 \times 10^{-7}$ \\
\hline & Lamb lettuce & $0.07 \pm 0.02 \mathrm{ab}$ & $0.07 \pm 0.02 b$ & $0.09 \pm 0.03 a$ & 20 & 0.0288 \\
\hline
\end{tabular}

*Due to low germination of savory cabbage seeds, only 10 plants per treatment were analysed

${ }^{a}$ The mean value followed by the standard deviation

${ }^{\mathrm{b}}$ Tukey post hoc test; mean values in a row with the same letters are not significantly different $(P=0.05)$; ns not significant

${ }^{c} P$ value of the ANOVA analysis 
Table 3 Draft genome sequencing and assembly statistics of Streptomyces spp. DEF1AK and DEF147AK

\begin{tabular}{lllllllllll}
\hline Strain & $\begin{array}{l}\text { Total } \\
\text { reads }\end{array}$ & $\begin{array}{l}\text { Mean } \\
\text { coverage }(\mathbf{X})\end{array}$ & $\begin{array}{l}\text { No. } \\
\text { scaffolds }\end{array}$ & $\begin{array}{l}\mathbf{N}_{\text {50 }} \\
(\mathbf{b p})\end{array}$ & $\begin{array}{l}\text { Assembly } \\
\text { length (bp) }\end{array}$ & $\begin{array}{l}\text { G+C } \\
\text { content (\%) }\end{array}$ & $\begin{array}{l}\text { Total No. } \\
\text { genes }\end{array}$ & $\begin{array}{l}\text { Avg. CDS } \\
\text { length (bp) }\end{array}$ & $\begin{array}{l}\text { No. } \\
\text { rRNAs }\end{array}$ & $\begin{array}{l}\text { No. } \\
\text { tRNAs }\end{array}$ \\
\hline DEF1AK & $1,155,828$ & $48 x$ & 131 & 107,416 & $7,095,674$ & 73.46 & 6646 & 968 & 4 & 65 \\
DEF147AK & $1,272,519$ & $50 x$ & 125 & 119,828 & $7,097,259$ & 73.45 & 6620 & 978 & 4 & 69 \\
\hline
\end{tabular}

them. Despite such a high similarity, the two strains showed clearly different plant growth and biocontrol potential. While DEF147AK inhibited a variety of fungal plant pathogens to a higher extent in vitro and showed high variability in promotion or inhibition of plant growth, DEF1AK proved to control better the Fusarium foot and root rot in planta. The ability to have higher activity in planta can be partially explained by the analyses of duplicate tandem genes (Supplementary file 3) which indicate potential selective pressure to maintain functional redundancy (Bratlie et al. 2010; Kondrashov 2012). Indeed, DEF1AK has a larger number of duplicated genes, such as ABC transporters, which can partially explain its better fitness in planta conditions. Both strains presented a set of duplicated chitinases that can act as effectors in the limitation of fungal growth in vitro. Moreover, Palazzini et al. (2017, 2018) demonstrated the activity of S. albidoflavus RC 87B against pathogenic Fusarium graminearum and deoxynivalenol (DON) accumulation in field conditions. Their results together with the DEF1AK activity in planta indicate the presence of specific secondary metabolites within the S. albidoflavus cluster able to counteract Fusarium species and DON accumulation.

Based on the genomic data, both strains have the potential to produce a variety of secondary metabolites, documented by the presence of 29 and 33 biosynthetic clusters in DEF1AK and DEF147AK, respectively. The differences in the secondary metabolite arsenal may explain the different biocontrol and PGP potential of the two strains.

Overall, our comparative report integrating biological activity with genomic data of two biologically active Streptomyces strains can open the way towards the effective exploitation of these strains as PGP and biological control agents, deciphering the functional determinants of the bioactive characters (Malik et al. 2020). Further studies will determine if the subtle differences in the two genomes are responsible for the differential synthesis of biologically active compounds and if these are responsible for the differences in the biocontrol and plant growth promotion activity of the two strains.

\section{Materials and methods}

\section{Streptomyces strains}

The two Streptomyces spp. strains, DEF1AK and DEF147AK, used in this work are part of a wide actinomycete collection isolated from roots of various plants and conserved in the laboratory of Plant Pathology, at the Department of Food, Environmental and Nutritional Sciences (DeFENS), University of Milan, Italy (Sardi et al. 1992). DEF1AK was isolated from the root cortical layer of Amaryllis belladonna and DEF147AK from the root cortical layer of Betula pendula. Strains were grown on Czapek-Yeast Extract medium (CZY: 35 g/L Czapek Dox broth, Difco Laboratories, Detroit, MI, USA; 2 g/L yeast extract, Difco Laboratories, Detroit, MI, USA; 15 g/ L agar, Applichem, Darmstadt, Germany) for 3 weeks at $24{ }^{\circ} \mathrm{C}$. Spores were collected in $10 \%$ sterile glycerol (ICN Biomedicals, Irvine, CA, USA) $+0.01 \%$ tween 20 (SigmaAldrich, St. Louis, MO, USA) and filtered through two layers of sterile gauze. The concentration was determined by plating serial dilutions of spore suspension and calculating the $\mathrm{CFU} / \mathrm{ml}$, and the spore suspension was stored at $-20^{\circ} \mathrm{C}$.

\section{Fungal plant pathogens}

Botrytis cinerea BC-2F-2016, BC-3F-2016, and BC-4F2016; Fusarium graminearum PH1 (Cuomo et al. 2007), NRRL 28336 (Pasquali et al. 2016), 453 (Pasquali et al. 2013a), Fg8/1 (Boenisch and Schäfer 2011), and CS3005 (Gardiner et al. 2014); F. culmorum FcUK (Pasquali et al. 2013b); Sclerotinia sclerotiorum FW361, SSP2, and SSV1; and Pythium ultimum FW407 belong to a collection maintained in the laboratory of Plant Pathology at DeFENS, University of Milan, Italy. Rhizoctonia solani FW408 was kindly provided by Dr. Andrea Minuto (Centro di Sperimentazione e Assistenza Agricola, Albenga, Italy). The pathogens were maintained on Malt-Extract Agar medium (MEA: $30 \mathrm{~g} / \mathrm{L}$ malt extract, Difco Laboratories, Detroit, MI, USA; 15 g/L agar, Applichem, Darmstadt, Germany) at $20^{\circ} \mathrm{C}$.

\section{Dual culture assay in vitro}

The biological activity of the two Streptomyces strains was evaluated as described in Kunova et al. 2016. Briefly, the pathogen agar-mycelium disc (6-mm diameter), taken from the edge of an actively growing fungal colony, was inoculated upside down in the centre of the Petri plate containing $\mathrm{CZY}$, whereas $10 \mu \mathrm{L}$ of streptomycete agar-spore suspension $\left(10^{7} \mathrm{CFU} / \mathrm{mL}\right)$ were uniformly distributed along a 40-mm line. The inoculation distance between the pathogen and the Streptomyces strain, the day of pathogen inoculation, and the day of the measurement varied based on the growth rate of the pathogen (Table 4). 
Three replicates were prepared for each strain, and plates inoculated only with the pathogen were used as control. Following the inoculation, plates were incubated in dark at $24^{\circ} \mathrm{C}$. The antagonistic activity was expressed as the percentage of mycelium growth inhibition compared to the control. It was calculated by the formula: $(\mathrm{R} 1-\mathrm{R} 2) / \mathrm{R} 1 \times 100$, where $\mathrm{R} 1$ was the radius measurement from the centre of the fungal colony towards the edge in the control and R2 was the radius from the centre towards the edge of the fungal colony in the direction of the antagonist, respectively.

\section{Effect of Streptomyces spp. on seed germination in vivo}

Seeds of monocotyledonous plants maize (Zea mays L.), rice (Oryza sativa L., 'Carnaroli') and wheat (Triticum aestivum L., 'Bandera'), and dicotyledonous plants tomato (Solanum lycopersicum L., 'Marmande'), cultivated rocket (Eruca sativa Mill.), savoy cabbage (Brassica oleracea L., 'Piacentino'), cauliflower (Brassica oleracea L., 'Violetto di Sicilia'), soybean (Glycine $\max$ (L.) Merr.), lettuce (Lactuca sativa L., 'Bionda ricciolina'), and lamb lettuce (Valerianella locusta L., 'Accent') were surface sterilized in $0.7 \%$ sodium hypochlorite for $5-10 \mathrm{~min}$ and rinsed three times abundantly in sterile water. Subsequently, they were bacterized by immersion of the seeds in a sufficient amount of Streptomyces spore suspension $\left(10^{7} \mathrm{CFU} / \mathrm{mL}\right)$ and letting them air-dry under the laminar flow hood. Control seeds were treated with sterile water. The seeds were sown in polystyrene seed trays (84 cells $-48 \mathrm{~cm}^{3}$ each) in the non-sterilized Irish and Baltic peat-based growing substrate (Vigorplant, Italy). The germination was assessed at varying times based on the plant species, and the germination percentage was calculated by the formula $G \%=G / T^{*} 100$, where $G \%=$ percentage of germination, $G=$ number of germinated seeds, and $T=$ total number of seeds.

\section{Effect of Streptomyces spp. on plant biomass in vivo} Seeds of diverse plant species were bacterized by the two Streptomyces spp. strains as described above and sown in the non-sterilized Irish and Baltic peat-based growing substrate (Vigorplant, Italy) in plastic boxes $(10 \times 10 \times$ $10 \mathrm{~cm}$ ) or polystyrene seed trays ( 84 cells $-48 \mathrm{~cm}^{3}$ each). The plants were grown in the growth chamber at $24{ }^{\circ} \mathrm{C}$, $55 \%$ relative humidity, and a $15-\mathrm{h}$ photoperiod and watered as necessary with tap water to keep the soil moist. After 1 month of growth (25 days in the case of wheat seedlings), the plants were carefully removed from the boxes, and the growing substrate was carefully removed from roots. Twenty plantlets per treatment were counted (ten plants for the savoy cabbage), left to air-dry at room temperature, and the biomass dry weight was determined.

Biocontrol potential of the two Streptomyces spp. strains against Fusarium graminearum on wheat seedlings

The biocontrol potential of the Streptomyces spp. strains against Fusarium root rot (FRR) and foot rot (FFR) was evaluated using F. graminearum Fg8/1-infected seedlings, as described in Colombo et al. (2019a). In detail, seeds of Triticum aestivum L. 'Bandera' were surfacesterilized in $0.7 \%$ sodium hypochlorite for $5 \mathrm{~min}$ and rinsed 3 times in sterile water. In sterile Petri dishes, seeds $(N=20)$ were inoculated with $1 \mathrm{~mL}$ of Streptomyces strain spore suspension $\left(10^{7}\right.$ spores $\left./ \mathrm{mL}\right)$ and dried under the laminar flow hood. Control seeds were treated with $1 \mathrm{~mL}$ of deionized sterile water. The assay took place in sterile glass dishes as seed trays (diameter 150 $\mathrm{mm}$ ). In each dish, a filter paper was placed and soaked with $10-\mathrm{mL}$ deionized sterile water before sowing. The dishes were placed at $5{ }^{\circ} \mathrm{C}$ in the dark for $24 \mathrm{~h}$ simulating a period of vernalization and then moved at $20^{\circ} \mathrm{C}$ in the dark. Seventy-two hours after seed bacterization, dishes were placed in a growth chamber $\left(21^{\circ} \mathrm{C}, 16\right.$-h photoperiod using fluora lamp Osram L36W/77). Seedlings were watered with sterile deionized water every 2 days. Four days after seed bacterization, the seedlings were inoculated with an agar-mycelium plug (6-mm diameter) taken from the edge of an actively growing $F$. graminearum Fg8/1 colony and inoculated upside down on the roots at a $10-\mathrm{mm}$ distance from the seed.

Table 4 Parameters of the in vitro antibiosis assay

\begin{tabular}{lllll}
\hline Fungal plant pathogen & Inoculation distance & Streptomyces inoculation & Fungus inoculation & Measurement \\
\hline Botrytis cinerea BC-2F-2016, BC-3F-2016, BC-4F-2016 & $2.0 \mathrm{~cm}$ & Day 1 & Day 3 & Day 6 \\
Fusarium graminearum PH1, 453, NRRL 28336 & $2.5 \mathrm{~cm}$ & Day 1 & Day 3 & Day 5 \\
Fusarium graminearum CS3005 & $2.0 \mathrm{~cm}$ & Day 1 & Day 1 & Day 4 \\
Fusarium culmorum FCUK & $2.0 \mathrm{~cm}$ & Day 1 & Day 3 & Day 5 \\
Pythium ultimum FW407 & $2.5 \mathrm{~cm}$ & Day 1 & Day 1 & Day 4 \\
Rhizoctonia solani FW408 & $2.0 \mathrm{~cm}$ & Day 1 & Day 1 & Day 4 \\
Sclerotinia sclerotiorum FW361, SSP2, SSV1 & $2.5 \mathrm{~cm}$ & Day 1 & Day 3 & Day 5 \\
\hline
\end{tabular}

The distance of inoculation between the Streptomyces and fungal plant pathogen, the timing of Streptomyces and fungal plant pathogen inoculation, and the timing of the fungal radial growth measurement 
Four days after pathogen inoculation FRR was measured on 20 roots as necrosis development. FRR data were reported as millimetres of necrosis extension. Percentages of necrosis inhibition (NI\%) were calculated by comparing measurements of necrosis on the control $\left(N_{\mathrm{C}}\right)$ and the treated seedlings $\left(N_{\mathrm{T}}\right)$ using the equation: $\mathrm{NI} \%=\left(N_{\mathrm{C}}-N_{\mathrm{T}}\right) / N_{\mathrm{C}} \times 100$.

Six days after pathogen inoculation, FFR was evaluated by scoring the symptoms at the crown level on 20 seedlings (Covarelli et al. 2013) with a $0-4$ scale $(0=$ symptomless; 1 = slightly necrotic; $2=$ moderately necrotic; 3 $=$ severely necrotic; $4=$ completely necrotic). The FFR disease severity index (DSI) was calculated for each treatment using the equation: DSI $=$ (disease grade $\times$ number of plants in each grade)/(total number of plants $\times$ the highest disease grade) $\times 100$. The ability of Streptomyces spp. strains to reduce FFR symptoms was calculated as protection percentage $(P \%)$ which was calculated using the equation $P \%=\left(\mathrm{DSI}_{\mathrm{C}}-\mathrm{DSI}_{\mathrm{T}}\right) / \mathrm{DSI}_{\mathrm{C}}$ $\times 100$, where $\mathrm{DSI}_{\mathrm{C}}$ and $\mathrm{DSI}_{\mathrm{T}}$ were the DSI in control and treated seedlings, respectively.

\section{DNA extraction and genome sequencing}

To obtain the DNA for the genome sequencing, the spore suspensions were inoculated in a Czapek Yeast Extract liquid medium ( $35 \mathrm{~g} / \mathrm{L}$ Czapek dox broth, Difco Laboratories, USA, $2 \mathrm{~g} / \mathrm{L}$ yeast extract, Difco Laboratories, USA) and grown for 7 days at $25^{\circ} \mathrm{C}$ with a $100 \mathrm{rpm}$ constant orbital shaking. The mycelium and spores were collected by centrifugation and the DNA was extracted and purified using the CTAB procedure for the isolation of genomic DNA (Kieser et al. 2000). The total DNA was randomly fragmented by sonication and the sequencing library was prepared using the Kapa HyperPrep Kit (Roche, Switzerland). Sequencing was carried out using the Illumina NextSeq 500/550 Mid Output v2 Kit (Illumina Inc., USA) on Illumina NextSeq 500 system. The draft genomes were assembled using EvoCAT (Evogene Clustering and Assembly Toolbox), which is a part of Evogene's computational biology predictive (CPB) platform (https://www.evogene.com) and annotated using MicroScope platform (Vallenet et al. 2019).

\section{Supplementary Information}

The online version contains supplementary material available at https://doi. org/10.1186/s13213-020-01616-2.

Additional file 1: Table S1. Clustering of Streptomyces spp. DEF1AK and DEF147AK CDS based on the EggNOG orthology (Huerta-Cepas et al. 2016; Vallenet et al. 2019)

Additional file 2: Table S2. Secondary metabolite analysis of Streptomyces albidoflavus DSM 40455 T, ACT77, SM 254, DEF1AK and DEF147AK by AntiSMASH based on homology to genome clusters from the database (Blin et al. 2019; Kautsar et al. 2020)
Additional file 3: Table S3. List of genomic regions containing tandem duplications of protein coding genes. Tandem duplicated genes have an identity $\geq 35 \%$ with a minLRap $\geq 0.8$ and are separated by a maximum of 5 consecutive genes. Begin: starting position of the genomic region; End: end position of the genomic region; Gene number: number of tandem duplicated genes contained in the genomic region; Genes: description of the tandem duplicated genes with their label, gene name and product description (Vallenet et al. 2019)

\section{Acknowledgements}

Not applicable.

\section{Authors' contributions}

AK and MP planned and conceived the work; AK, MP, GM, and MS performed the experiments; and $\mathrm{AK}, \mathrm{MP}$, and $\mathrm{PC}$ analysed and interpreted the data. AK, MP, MS, and PC wrote the manuscript. All authors read and approved the final manuscript.

\section{Funding}

The research was supported by the University of Milan - Linea 2 project MYFENS.

\section{Availability of data and materials}

All data generated or analysed during this study are included in this published article and its supplementary information files, while the draft genome sequences described have been deposited in NCBI GenBank under BioProject number PRJNA649699, BioSample numbers SAMN15677290 for DEF1AK, and SAMN15677291 for DEF147AK. Raw sequencing data were deposited in the NCBI Short Read Archive under the same BioProject number, with accession number SRR13189637 and SRR13189636, respectively.

Ethics approval and consent to participate

Not applicable

\section{Consent for publication}

Not applicable

\section{Competing interests}

The authors declare that they have no competing interests.

\section{Author details}

${ }^{1}$ Department of Food, Environmental and Nutritional Sciences (DeFENS), University of Milan, Via Celoria 2, Milan, Italy. ${ }^{2}$ Lavie Bio, P.O.Box 4173, 7414004 Ness Ziona, Israel.

Received: 15 October 2020 Accepted: 23 December 2020

Published online: 06 January 2021

\section{References}

Badalamenti JP, Erickson JD, Salomon CE (2016) Complete genome sequence of Streptomyces albus SM254, a potent antagonist of bat white-nose syndrome pathogen Pseudogymnoascus destructans. Genome Announc 4:. https://doi. org/https://doi.org/10.1128/genomeA.00290-16

Blin K, Shaw S, Steinke K, et al (2019) antiSMASH 5.0: updates to the secondary metabolite genome mining pipeline. Nucleic Acids Res 47:81-87. https://doi. org/https://doi.org/10.1093/nar/gkz310

Boenisch MJ, Schäfer W (2011) Fusarium graminearum forms mycotoxin producing infection structures on wheat. BMC Plant Biol 11:110. https://doi org/https://doi.org/10.1186/1471-2229-11-110

Bonaldi M, Kunova A, Saracchi M et al (2014) Streptomycetes as biological control agents against basal drop. Acta Hortic (1044):313-318

Bratlie MS, Johansen J, Sherman BT, et al (2010) Gene duplications in prokaryotes can be associated with environmental adaptation. BMC Genomics 11:588. https://doi.org/https://doi.org/10.1186/1471-2164-11-588

Chen X, Pizzatti C, Bonaldi M, et al (2016) Biological control of lettuce drop and host plant colonization by rhizospheric and endophytic streptomycetes. Front Microbiol 7:714. https://doi.org/https://doi.org/10.3389/fmicb.2016.00714 
Chevrette MG, Carlson CM, Ortega HE, et al (2019) The antimicrobial potential of Streptomyces from insect microbiomes. Nat Commun 10:1-11. https://doi. org/https://doi.org/10.1038/s41467-019-08438-0

Čihák M, Kameník Z, Šmídová K, et al (2017) Secondary metabolites produced during the germination of Streptomyces coelicolor. Front Microbiol 8:2495. https://doi.org/https://doi.org/10.3389/fmicb.2017.02495

Colombo EM, Kunova A, Pizzatti C, et al (2019a) Selection of an endophytic Streptomyces sp. strain DEF09 from wheat roots as a biocontrol agent against Fusarium graminearum. Front Microbiol 10:2356. https://doi.org/https://doi. org/10.3389/fmicb.2019.02356

Colombo EM, Pizzatti C, Kunova A, et al (2019b) Evaluation of in-vitro methods to select effective streptomycetes against toxigenic fusaria. PeerJ 7:e6905. https://doi.org/https://doi.org/10.7717/peerj.6905

Covarelli L, Gardiner D, Beccari G, Nicholson P (2013) Fusarium virulence assay on wheat and barley seedlings. BIO-PROTOCOL 3:. https://doi.org/https://doi.org/ 10.21769/bioprotoc.446

Cuomo CA, Güldener U, Xu J-R, et al (2007) The Fusarium graminearum genome reveals a link between localized polymorphism and pathogen specialization. Science (80- ) 317:1400-1402. https://doi.org/https://doi.org/10.1126/science. 1143708

Gardiner DM, Stiller J, Kazan K (2014) Genome sequence of Fusarium graminearum isolate CS3005. Genome Announc 2:e00227-e00214. https://doi. org/https://doi.org/10.1128/genomeA.00227-14

Guo YP, Zheng W, Rong XY, Huang Y (2008) A multilocus phylogeny of the Streptomyces griseus 165 rRNA gene clade: use of multilocus sequence analysis for streptomycete systematics. Int J Syst Evol Microbiol 58:149-159. https://doi.org/https://doi.org/10.1099/ijs.0.65224-0

Hain T, Ward-Rainey N, Kroppenstedt RM, et al (1997) Discrimination of Streptomyces albidoflavus strains based on the size and number of 16S-23S ribosomal DNA intergenic spacers. Int J Syst Bacteriol 47:202-206. https://doi. org/https://doi.org/10.1099/00207713-47-1-202

Huerta-Cepas J, Forslund K, Coelho LP, et al (2017) Fast genome-wide functional annotation through orthology assignment by eggNOG-mapper. Mol Biol Evol 34:2115-2122. https://doi.org/https://doi.org/10.1093/molbev/msx148

Huerta-Cepas J, Szklarczyk D, Forslund K, et al (2016) EGGNOG 4.5: a hierarchical orthology framework with improved functional annotations for eukaryotic, prokaryotic and viral sequences. Nucleic Acids Res 44:D286-D293. https://doi. org/https://doi.org/10.1093/nar/gkv1248

Jauri PV, Altier N, Kinkel LL (2016) Streptomyces for sustainability. In: Microbial Models: From Environmental to Industrial Sustainability. Springer, Singapore, pp 251-276

Jolley KA, Maiden MCJ (2010) BIGSdb: Scalable analysis of bacterial genome variation at the population level. BMC Bioinformatics 11:595. https://doi.org/ https://doi.org/10.1186/1471-2105-11-595

Kautsar SA, Blin K, Shaw S, et al (2020) MIBiG 2.0: a repository for biosynthetic gene clusters of known function. Nucleic Acids Res 48:D454-D458. https:// doi.org/https://doi.org/10.1093/nar/gkz882

Kieser T, Bibb M, Buttner M et al (2000) Practical Streptomyces genetics. In: John Innes Foundation. Norwich, United Kingdom

Kondrashov FA (2012) Gene duplication as a mechanism of genomic adaptation to a changing environment. Proc R Soc B Biol Sci 279:5048-5057

Kunova A, Bonaldi M, Saracchi M, et al (2016) Selection of Streptomyces against soil borne fungal pathogens by a standardized dual culture assay and evaluation of their effects on seed germination and plant growth. BMC Microbiol 16:272. https://doi.org/https://doi.org/10.1186/s12866-016-0886-1

Lee N, Hwang S, Kim J et al (2020) Mini review: Genome mining approaches for the identification of secondary metabolite biosynthetic gene clusters in Streptomyces. Comput Struct Biotechnol J 18:1548-1556

Li Q, Song Y, Qin X, et al (2015) Identification of the biosynthetic gene cluster for the anti-infective desotamides and production of a new analogue in a heterologous host. J Nat Prod 78:944-948. https://doi.org/https://doi.org/10. 1021/acs.jnatprod.5b00009

Liu D, Yan R, Fu Y, et al (2019) Antifungal, plant growth-promoting, and genomic properties of an endophytic actinobacterium Streptomyces sp. NEAU-S7GS2. Front Microbiol 10:2077. https:/doi.org/https://doi.org/10.3389/fmicb.2019.02077

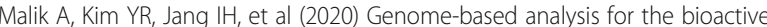
potential of Streptomyces yeochonensis CN732, an acidophilic filamentous soil actinobacterium. BMC Genomics 21:118. https://doi.org/https://doi.org/10. 1186/s12864-020-6468-5

Palazzini J, Roncallo P, Cantoro R et al (2018) Biocontrol of Fusarium graminearum sensu stricto, reduction of deoxynivalenol accumulation and phytohormone induction by two selected antagonists. Toxins (Basel) 10:88 https://doi.org/10 3390/toxins 10020088

Palazzini JM, Yerkovich N, Alberione E, et al (2017) An integrated dual strategy to control Fusarium graminearum sensu stricto by the biocontrol agent Streptomyces sp. RC 87B under field conditions. Plant Gene 9:13-18. https:// doi.org/https://doi.org/10.1016/j.plgene.2016.11.005

Pasquali M, Cocco E, Guignard C, Hoffmann L (2016) The effect of agmatine on trichothecene type B and zearalenone production in Fusarium graminearum, F. culmorum and F. poae. PeerJ 2016:e1672. https://doi.org/https://doi.org/10. 7717/peerj.1672

Pasquali M, Serchi T, Renaut J, et al (2013a) 2D difference gel electrophoresis reference map of a Fusarium graminearum nivalenol producing strain. Electrophoresis 34:505-509. https://doi.org/https://doi.org/10.1002/elps. 201200256

Pasquali M, Spanu F, Scherm B, et al (2013b) FcStuA from Fusarium culmorum controls wheat foot and root rot in a toxin dispensable manner. PLoS One 8 : e57429. https://doi.org/https://doi.org/10.1371/journal.pone.0057429

Pylro VS, Dias ACF, Andreote FD, et al (2019) Draft genomic sequences of Streptomyces misionensis ACT66 and Streptomyces albidoflavus ACT77, bacteria with potential application for phytopathogen biocontrol. Microbiol Resour Announc 8:949-968. https://doi.org/https://doi.org/10.1128/mra. 00949-19

Sardi P, Saracchi M, Quaroni S et al (1992) Isolation of endophytic Streptomyces strains from surface-sterilized roots. Appl Environ Microbiol 58:2691-2693

Seipke RF, Kaltenpoth M, Hutchings MI (2012) Streptomyces as symbionts: an emerging and widespread theme? FEMS Microbiol Rev 36:862-876. https:// doi.org/https://doi.org/10.1111/j.1574-6976.2011.00313.x

Vallenet D, Calteau A, Dubois M, et al (2019) MicroScope: an integrated platform for the annotation and exploration of microbial gene functions through genomic, pangenomic and metabolic comparative analysis. Nucleic Acids Res 48:579-589. https://doi.org/https://doi.org/10.1093/nar/gkz926

Velivelli SLSS, De Vos P, Kromann P, et al (2014) Biological control agents: from field to market, problems, and challenges. Trends Biotechnol 32:493-496. https://doi.org/https://doi.org/10.1016/j.tibtech.2014.07.002

Vesselinova N, Gesheva R, Ivanova V (1991) Streptomyces species producing the streptovaricin complex. Folia Microbiol (Praha) 36:538-541. https://doi.org/ https://doi.org/10.1007/BF02884033

Wang D, Yuan J, Gu S, Shi Q (2013) Influence of fungal elicitors on biosynthesis of natamycin by Streptomyces natalensis HW-2. Appl Microbiol Biotechnol 97: 5527-5534. https://doi.org/https://doi.org/10.1007/s00253-013-4786-0

Xiao K, Kinkel LL, Samac D a. (2002) Biological control of Phytophthora root rots on alfalfa and soybean with Streptomyces. Biol Control 23:285-295. https:// doi.org/https://doi.org/10.1006/bcon.2001.1015

Yoon SH, Ha S min, Lim J, et al (2017) A large-scale evaluation of algorithms to calculate average nucleotide identity. Antonie Van Leeuwenhoek 110:12811286. https://doi.org/https://doi.org/10.1007/s10482-017-0844-4

\section{Publisher's Note}

Springer Nature remains neutral with regard to jurisdictional claims in published maps and institutional affiliations.

Ready to submit your research? Choose BMC and benefit from:

- fast, convenient online submission

- thorough peer review by experienced researchers in your field

- rapid publication on acceptance

- support for research data, including large and complex data types

- gold Open Access which fosters wider collaboration and increased citations

- maximum visibility for your research: over $100 \mathrm{M}$ website views per year

At BMC, research is always in progress.

Learn more biomedcentral.com/submissions 